\title{
Intrathecal bupivacaine protects against extension of lesions in an acute photochemical spinal cord injury model
}

\author{
[L'administration intrathécale de bupivacaïne empêche l'extension des lésions chez \\ un modèle photochimique de lésion médullaire]
}

Sandrine Lopez MD, * Alain Privat MD PhD, $†$ Nathalie Bernard MD, * Freddy Ohanna MD PhD, Christine Vergnes MD, $\$$ Xavier Capdevila MD PhD*

Purpose: The photochemical spinal-cord injury model reproduces extensive secondary lesions that occur after spinal injury. We have evaluated in 27 rats the functional, electrophysiological and anatomical consequences of a photochemical spinal-cord lesion induced before or after intrathecal injection of bupivacaine.

Methods: After randomization, nine rats received $20 \mu \mathrm{L}$ of intrathecal bupivacaine $0.5 \% \quad 15 \mathrm{~min}$ before a photochemical spinal-cord lesion (Group I) and eight rats received $20 \mu \mathrm{L}$ intrathecal bupivacaine $15 \mathrm{~min}$ after such a lesion (Group II). Ten rats received $20 \mu \mathrm{L}$ of saline 15 min before the photochemical injury (control group).

Paraplegia was tested on days one, three, five, seven, nine, 12, 15 and 18 using an evaluation of hindlimb movements and an inclined plane stability test. Sensory block was evaluated by the animal's response when each hindlimb was brought into contact with a hot plate. Sympathetic injury was evaluated in terms of bladder voiding dysfunction. On day 18, residual somatosensory evoked potentials (SEP) were measured and the area of the intact spinal cord was determined using a digitalized system.

Results: Early paraplegia recovery was found in the two bupivacaine groups $(P<0.05)$. On day 12, motor recovery was complete in both bupivacaine groups whereas recovery was not complete on day 18 in the control group. Compared to the control group, inclined plane stability recovered earlier in Groups I and II, from day three to day I5. Sensory and sympathetic block scores were not different in the three groups. Nevertheless, SEP latencies were longer and amplitudes were lower in control group rats compared with the two bupivacaine groups on day 18. The intact spinal-cord cross-sectional area around the lesion was not different in the three groups.

Conclusion: Twenty microlitres of intrathecal bupivacaine before or after acute photochemical spinal injury improves hindlimb motor recovery and SEP parameters in rats.

Objectif : Le modèle photochimique d'une lésion médullaire reproduit les lésions secondaires extensives survenant après un traumatisme médullaire. Nous avons évalué, chez 27 rats, les conséquences fonctionnelles, électrophysiologiques et anatomiques d'une lésion médullaire photochimique induite avant ou après l'injection intrathécale de bupivacaine.

Méthode : Après répartition au hasard, neuf rats ont reçu $20 \mu \mathrm{L}$ de bupivacaïne intrathécale à 0,5\%, 15 min avant une lésion médullaire photochimique (Groupe I) et huit rats ont reçu $20 \mu \mathrm{L}$ de bupivacaïne intrathécale 15 min après une lésion similaire (Groupe II). Dix rats témoins ont reçu $20 \mu \mathrm{L}$ de solution saline 15 min avant la lésion.

La paraplégie a été évaluée aux jours un, trois, cinq, sept, neuf, 12 , 15 et 18 par l'examen des mouvements des membres postérieurs et par un test de stabilité sur plan incliné. Le bloc sensitif a été évalué par la réaction de l'animal lorsque chaque membre postérieur touche une plaque chauffante. La lésion sympathique a été évaluée en termes de dysfonction vésicale mictionnelle. Au jour 18, les potentiels évoqués somesthésiques (PES) résiduels ont été mesurés et l'aire intacte de la moelle a été déterminée par un système numérisé.

From the Department of Anesthesiology and Critical Care Medicine, ${ }^{*}$ Lapeyronie University Hospital; the Institut National de la Santé et de la Recherche Médicale (INSERM) Unité 336,† Université Montpellier II; the Centre Propara; $\ddagger$ and the DIM - Hôpital Arnaud de Villeneuve - C.H.U.,\$ Montpellier, France.

Address correspondence to: Dr. Xavier Capdevila, Département d'Anesthésie Réanimation A - Hôpital Lapeyronie, 371, Av du Doyen G Giraud, 34295 Montpellier Cedex 5, France. Phone: 003346733 8256; Fax: 003346733 7960; E-mail: x-capdevila@chu-montpellier.fr Work should be attributed to: Département d'Anesthésie Réanimation A - Hôpital Lapeyronie - CHU - Montpellier, France.

Sources of financial support: INSERM U336, Université Montpellier II - Montpellier, France. SEREP, Centre PROPARA, Parc Euromédecine - Montpellier, France. ADREFAR, DAR, Hôpital Lapeyronie - Montpellier, France.

Presented in part at the Annual meeting of IARS, Hawaï, March 9-12, 2000.

Accepted for publication October 22, 2003.

Revision accepted January 14, 2004. 
Résultats : On a observé une récupération précoce de la paraplégie chez les rats traités à la bupivacaïne $(P<0,05)$. Au jour 12, la récupération motrice était complète chez les rats sous bupivacaïne, mais incomplète au jour 18 chez les rats témoins. Comparés aux rats témoins, les rats des groupes I et II ont récupéré plus tôt une stabilité sur plan incliné, du jour trois au jour 15. Les valeurs du bloc sensitif et sympathique étaient similaires chez tous les rats. Néanmoins, au jour 18, les temps de latence des PES ont été plus longs et les amplitudes plus faibles chez les témoins que chez les rats des groupes I et II. L'aire intacte de la coupe transversale de la moelle autour de la lésion était semblable pour tous les rats.

Conclusion : Vingt microlitres de bupivacaïne intrathécale administrés avant ou après une lésion médullaire photochimique améliore la récupération de la fonction motrice des membres postérieurs et les paramètres des PES chez les rats.

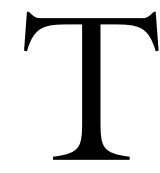

HE annual incidence of spinal cord injury (SCI), not including those who die at the scene of the accident, is approximately 40 cases per million population in the U.S. Eighty five percent of SCI patients who survive the first $24 \mathrm{hr}$ are still alive ten years later. Neurologic recovery is in general partial, related to the injury level but not to age. ${ }^{1}$ Cat models of lesions by impaction ${ }^{2,3}$ have been used to clarify the pathophysiology of secondary extension of traumatic injury. The main cause was observed to be ischemia of the gray matter, a consequence of the intracellular entry of calcium, and edema of the perilesional white matter. ${ }^{2,3}$ Experimentally, the photochemical model of a secondary lesion was described by Watson et al. ${ }^{4}$ in rats. The resultant photochemical reaction leads to vascular stasis and congestion, hemorrhagic necrosis of the central gray matter and edematous pale-staining white matter tracts. The induced lesion is reproducible and the procedure is easy to implement. This model reproduces the two major phenomena involved in the extension of post-traumatic secondary lesions, ischemic lesions created by platelet aggregation primarily affecting gray matter, and edema of the white matter. These lesions may be seen in ischemic spinal cord models due to aortic clamping. ${ }^{5,6}$

Various treatments have been proposed to prevent post-traumatic secondary lesions. Antagonists of opioid receptors (naloxone) ) $^{7,8}$ or gangliosides ${ }^{9}$ appreciably improve neuronal function in animal models but have given inconstant and disappointing results in human clinical trials. ${ }^{10}$ The administration of noncompetitive antagonists of $\mathrm{N}$-methyl-D-aspartate receptors (phencyclidine and ketamine) ${ }^{11}$ or of massive doses of steroids ${ }^{12}$ has a neuroprotective effect, but their use is limited by their respective side effects. Intrathecal injection of local anesthetics (bupivacaine, tetracaine) appreciably reduces the functional consequences to the spinal cord of aortic clamping in rabbits. ${ }^{5}$ Unfortunately, this encouraging report did not include studies of the structural and neurophysiological impact of the treatment on the spinal cord and on the secondary postischemic lesion. On the contrary, Wakamatsu et al..$^{6}$ demonstrate that, in rabbits, moderate hypothermia $\left(32^{\circ} \mathrm{C}\right)$, but not intrathecal tetracaine, significantly attenuated the increase in glutamate concentrations of intrathecal dialysate during spinal cord ischemia produced by occlusion of the abdominal aorta, and improved the neurologic and histopathologic outcome. These authors injected intrathecal tetracaine after the induced postischemic lesion. It should be interesting to see if a greater protective effect exists if the local anesthetic is injected before the lesion.

We hypothesized that bupivacaine could be a neuroprotective agent. The aim of the present study was to evaluate the efficacy of intrathecal bupivacaine administered before or after spinal-cord injury in term of functional, electrophysiological and anatomical consequences in a photochemical model of secondary spinal-cord lesion in rats.

\section{Material and methods}

This prospective randomized experimental study was conducted in male Spragues-Dawley rats seven and a half weeks old weighing from 218 to $350 \mathrm{~g}$ (Iffa Credo Company, Arbresle, France). It was approved by our Institutional Animal Investigation Committee.

There is no model in the literature of spinal anesthesia at the thoracic vertebral level in the rat. The difficulty in generating a limited thoracic block by means of a lumbar injection (with the risk of unacceptably low-metameric level or excessive blockade) prompted us to create a model of limited spinal anesthesia at the thoracic level in the rat. Bahar et al. ${ }^{13}$ observed that lumbar injection of $32 \mu \mathrm{L}$ of $2 \%$ lidocaine in rats lead to motor and sensory blocks of the hindlimbs. During preliminary experiments, we determined the dose necessary at the thoracic level to obtain a motor block of the hindlimbs. The first series of preliminary studies (two rats) consisted in the intrathecal injection of 25 $\mu \mathrm{L}$ of $0.5 \%$ bupivacaine through a thoracic catheter with the animals placed in a $10^{\circ}$ Fowler position. Both rats died of respiratory arrest immediately after the injection (total spinal anesthesia). In two other rats, we tested $20 \mu \mathrm{L}$ of intrathecal bupivacaine. Neither animal had a respiratory arrest. Both awakened with hindlimb motor block, which totally resolved eight 
hours later. Thus we chose to use $20 \mu \mathrm{L}$ of bupivacaine at the thoracic level in animals placed in a $10^{\circ}$ Fowler position.

The rats were randomly distributed into three groups. The randomization technique was by computer-generated random number. Group I received $20 \mu \mathrm{L}$ of intrathecal bupivacaine $15 \mathrm{~min}$ before the photochemical lesion, Group II received $20 \mu \mathrm{L}$ of intrathecal bupivacaine $15 \mathrm{~min}$ after the photochemical lesion, and a control group received $20 \mu \mathrm{L}$ of intrathecal saline 15 min before the photochemical lesion.

The experiment was carried out in a quiet room maintained at a temperature ranging between 18 and $22^{\circ} \mathrm{C}$. An artificial day-night cycle was not used. Every rat occupied an individual cage of $0.016 \mathrm{~m}^{3}$ and had access ad libitum to food and water. During the study, the bladder was emptied daily by manual pressure until sphincter function returned to normal. Every animal received $12 \mathrm{mg} \cdot \mathrm{kg}^{-1} \cdot \mathrm{day}^{-1}$ of gentamicin intraperitoneally for seven days following lesion induction.

The day the lesion was induced was considered day zero. The induction of anesthesia used an $i p$ mixture of pentobarbital $\left(0.9 \mathrm{~g} \cdot 100 \mathrm{~mL}^{-1}\right)$ and chloral hydrate $\left(4.2 \mathrm{~g} \cdot 100 \mathrm{~mL}^{-1}\right)$ in saline. Anesthesia was maintained with $0.1 \mathrm{~mL} i v$ injections of this mixture as needed when the rat showed signs of awakening. Weight on day zero (weight D0) was measured 15 min after induction of anesthesia. After catheterization of the left dorsolateral vein of the tail for saline infusion and $i v$ access, the operation was performed under an operating microscope, a dorsal skin incision was made and a laminectomy was performed at T8 to expose the dura mater. A 24-gauge intrathecal catheter (Vermed, Neuilly-enThelle, France) was inserted and pushed $2 \mathrm{~cm}$ in a rostral direction. A $100-\mu \mathrm{L}$ glass syringe was used to inject either bupivacaine or saline through the catheter. After the intrathecal injection, the cephalad end of the table was raised $10^{\circ}$. The catheter was left in place for 15 min. Animals were maintained at $37^{\circ} \mathrm{C}$ with an electric blanket connected to a regulating thermometer (Harvard Instruments, Boston, MA, USA). Bupivacaine at a concentration of $0.5 \%$ was used without additive (Astra-Zeneca, Nanterre, France).

The photochemical lesion was induced according to the protocol described by Watson $e t a l^{4}$ This is a minimally invasive model of reproducible SCI initiated photochemically. A $560-\mathrm{nm}$ irradiation of the translucent dorsal surface of the exposed spinal column induces excitation of the injected Rose Bengal in the spinal cord microvasculature. Every rat received $40 \mathrm{mg} \cdot \mathrm{kg}^{-1}$ of Rose Bengal (Aldrich Chemical Co. Milwaukee, WI, USA) intravenously, immediately after which the animal was exposed to light from a
TABLE I Motor score for unprompted walking

\begin{tabular}{ll}
\hline 50 & No movement of the hindlimbs \\
40 & Barely perceptible movements of the hindlimbs \\
30 & Vigorous and/or frequent movements of the hindlimbs \\
20 & The hindlimbs bear the weight of the body \\
10 & Walking with a patent deficit \\
0 & Normal walking \\
\hline
\end{tabular}

TABLE II Stability scores on an inclined plane

\begin{tabular}{ll}
\hline 30 & $<35^{\circ}$ \\
20 & $35^{\circ}$ to $45^{\circ}$ \\
10 & $45^{\circ}$ to $60^{\circ}$ \\
0 & $>65^{\circ}$ \\
\hline
\end{tabular}

xenon lamp (ILC Technology, Sunnyvale, CA, USA) for four minutes. The focused beam of the lamp was transmitted by optical fibres and directed at the vertebral level T7. The fibreoptic beam had an exit-point power of 0.82 watts per $\mathrm{cm}^{2}$. Power was verified daily and the lamp recalibrated as necessary. To avoid thermal injury while inducing the photochemical lesion, two small lamp ventilators were used. After the experiment, the animal was placed in its cage until completely awake.

Motor function was evaluated on day one, day three, day five, day seven, day nine, day 12 , day 15 and day 18 after the lesion. These evaluations were performed at the same moment of day by the same investigator, who was unaware of the group assignment. Mobility was assessed roughly by a test of unprompted walking and by a test of stability on an inclined plane. The scoring systems used ${ }^{14}$ are shown in Tables I and II. The quality of unprompted walking was assessed by observing the rat's movements without stimulation on a smooth horizontal plane for three minutes. The inclined-plane stability test was carried out by placing the rat on a plane which was horizontal initially, then successively tilted $5^{\circ}$ every $30 \mathrm{sec}$ and noting the angle at which the rat lost its balance. Concerning the two motor tests, the lower the score was, better was the improvement. Sensory blockade was tested by noting the withdrawal of hind paws during contact with a hot plate at $90^{\circ} \mathrm{C}$. The cut-off time was fixed at $20 \mathrm{sec}$ to prevent thermal injury. There were three types of response to this test: $\mathrm{Y}$ (yes) for adapted withdrawal, $\mathrm{N}$ (no) for absence of withdrawal, or $\mathrm{H}$ for hyperactive flexion, equivalent to a liberated spinal reflex. Sympathetic blockade was considered to exist if the animal had voiding dysfunction. ${ }^{15}$

On day 18, every rat underwent somatosensory evoked potential (SEP) studies. These were conduct- 
ed according to the protocol of Baskin et al. ${ }^{16}$ Under general anesthesia induced by the same mixture as day zero, the right sciatic nerve was exposed under the operating microscope. After trepanation was performed over the somatosensory area $(1 \mathrm{~mm}$ to the left of the median line and $3 \mathrm{~mm}$ posterior to the coronal suture), a subdural detection electrode connected with the anode was inserted in the somatopic area corresponding to the right hindlimb, the reference electrode under the skin of the snout, and the ground electrode subcutaneously at the back. Stimulation was applied to the right sciatic nerve at a frequency of 3.7 $\mathrm{Hz}$ with a suprathreshold current of $\mathrm{l}$ to $3.3 \mathrm{~mA}$, which produced a muscle twitch. The signal was filtered (Pathfinder II Nicolet Biomedical Instrument, Madison, WI, USA) and amplified. Two hundred responses with an acquisition time of $120 \mathrm{msec}$ were averaged. For each animal, two superimposable responses were recorded. SEP were analyzed for latencies (Pl: first positive deflection, $\mathrm{Nl}$ : first negative deflection, and P2: second positive deflection) and amplitudes (P1N1 and P2N2).

After SEP acquisition, the animal was sacrificed by ip injection of $1 \mathrm{~mL}$ of pentobarbital $\left(6 \mathrm{~g} \cdot 100 \mathrm{~mL}^{-1}\right)$ for pathological analysis of the spinal cord. Thoracotomy, phrenotomy, and laparotomy were performed. Intracardiac injection of $1 \mathrm{~mL}$ heparin and $\mathrm{l}$ $\mathrm{mL}$ of $1 \%$ sodium nitrite preceded catheterization of the thoracic aorta by which $50 \mathrm{~mL}$ of saline were infused. This was followed by an infusion of $500 \mathrm{~mL}$ of fixative ( $4 \%$ paraformaldehyde in $0.12 \mathrm{M}$ phosphate buffer at $\mathrm{pH} 7.4$ ). The spinal cord was left in situ one night at $4^{\circ} \mathrm{C}$, then removed by laminectomy from the cervical to the lumbar vertebrae. The spinal lesion was identified and a $15-\mathrm{mm}$ segment of the spinal cord centered around the photochemical lesion was postfixed at least $24 \mathrm{hr}$, at $4^{\circ} \mathrm{C}$ in the same solution. This block was then immersed in a pressure gradient of saccharose, placed in a cryoembedding media, frozen in liquid nitrogen and stored at $-50^{\circ} \mathrm{C}$ until sectioning. Cross sections $16 \mu \mathrm{m}$ in thickness were cut on a cryostat at $-20^{\circ} \mathrm{C}$ (Microm HM 500, London, UK). Sections were collected on gelatin-coated slides and inspected under 2.5-fold magnification (Axioscope, M, Zeiss, Ulm, Germany). Beginning at one extremity of the spinal-cord segment, one section out of fifty was examined until the lesion was reached. In the injured portion of the segment, one section out of 25 was examined (i.e., one section every $384 \mu$ ) until reaching the other side of the segment exempt from lesion. All sections were dried for six hours at ambient laboratory temperature, then stored at $-20^{\circ} \mathrm{C}$ in the cryostat. At ambient temperature, the sections were stained by immersion in cresyl violet, rinsed in successive baths of $9 \%$ alcohol, then $100 \%$ alcohol, and mounted. All the intralesional sections were observed and the one in which the cross sectional area of healthy spinal cord was the smallest was digitized using a SAMBA 2005 system (Alcatel, Grenoble, France) with an IBM-compatible computer. The outlines of the residual healthy spinal cord were drawn on the screen, after subtraction of the background noise. The total surface of intact spinal cord, expressed in $\mathrm{mm}^{2}$, was calculated. To compensate for variations in drawing of the outline, measurements were repeated three times by the same physician. The average of these three measurements was retained. ${ }^{17}$

\section{Statistics}

Sample size calculation: a $10 \%$ beta risk was retained for an anticipated 30\% intergroup difference concerning motor function tests, SEP's amplitudes and surface area of healthy spinal cord. The study was originally designed to include eight rats in each group. Data are expressed as medians (above the 25th percentile and below 75 th percentile). The analysis of the course of motor functional scores over time in each of the groups was performed using the Friedman test (analysis of variance for repeated measurements, non-parametric test). Comparisons of motor functional scores between groups at each time of assessment were made by means of Wilcoxon-Mann-Whitney (comparison of two groups) or of Kruskal-Wallis (comparison of more than two groups) tests because non-Gaussian variables and/or ordinal data were involved. When a significant difference between more than two medians was found these were compared two-by-two applying a Bonferroni correction. Comparisons between the groups at each assessment time for the course of the sensory blockade and the autonomous system were performed using Chisquare tests, or Fischer exact tests when the conditions of validity of Chi-square were not met. A test was considered significant if $P<0.05$.

\section{Results}

Groups I, II and control counted nine, eight and ten rats, respectively. On the day of the lesion (day zero), the average weight of each group was 283.2, 240.7 and $296.1 \mathrm{~g}$, respectively. The weight of the rats in Group II was significantly lower $(P<0.05)$. This difference in weight did not persist at day 18 . Furthermore, there was no difference in weight gained (Table III).

Motor functional evaluation immediately after the photochemical lesion was not different between the three groups (Table IV). On day three, the control 
TABLE III Weight [median (25-75th centiles)] for the three groups

\begin{tabular}{llll}
\hline & Weight DO $(g)$ & Weight D18 (g) & Weight gain (\%) \\
\hline Group I & $283.2(268.9-300.4)$ & $347.4(321.3-376.5)$ & $21(18-35)$ \\
Group II & $240.7(232.5-245.7)^{*}$ & $310.6(296-328)$ & $35.5(19-41)$ \\
Group III & $296.1(289.8-328.6)$ & $339(295.1-374.4)$ & $10(2-26)$ \\
\hline
\end{tabular}

${ }^{*} P<0.05$. Group I = bupivacaine before; Group II = bupivacaine after; Group III $=$ control .

TABLE IV Unprompted walking scores in the three groups; median (25-75th centiles)

\begin{tabular}{|c|c|c|c|c|c|c|c|c|}
\hline & $D 1$ & D3 & D5 & D7 & D9 & $D 12$ & D15 & D18 \\
\hline Group I & $40(30-40)$ & $40(30-40)^{*}$ & $40(30-40)^{*}$ & $0(0-20)^{*}$ & $0(0-0)^{*}$ & $0(0-0)^{*}$ & $0(0-0)^{*}$ & $0(0-0)^{*}$ \\
\hline Group II & $40(30-45)$ & $40(30-40)^{*}$ & $30(20-40)^{*}$ & $20(10-30)^{*}$ & $10(0-20)^{*}$ & $0(0-10)$ & $0(0-10)$ & $0(0-10)$ \\
\hline Group III & $50(40-50)$ & $50(50-50)$ & $50(50-50)$ & $40(30-40)$ & $30(20-30)$ & $30(0-30)$ & $10(0-30)$ & $10(0-30)$ \\
\hline
\end{tabular}

${ }^{*} P<0.05$. Group I = bupivacaine before; Group II = bupivacaine after; Group III = control .

TABLE V Stability scores on an inclined plane in the three groups (median 25-75th centiles)

\begin{tabular}{lllllllll}
\hline & $D 1$ & $D 3$ & $D 5$ & $D 7$ & $D 9$ & $D 12$ & $D 15$ & $D 18$ \\
\hline Group I & $20(20-30)$ & $20(20-20)^{*}$ & $20(10-30)^{*}$ & $10(0-20)^{*}$ & $0(0-0)^{*}$ & $0(0-10)^{*}$ & $0(0-10)^{*}$ & $0(0-0)$ \\
Group II & $20(10-30)$ & $20(20-30)^{*}$ & $20(10-20)^{*}$ & $0(0-10)^{*}$ & $0(0-10)^{*}$ & $0(0-10)^{*}$ & $0(0-10)^{*}$ & $0(0-10)$ \\
Group III & $30(20-30)$ & $30(30-30)$ & $30(20-30)$ & $20(20-30)$ & $10(10-20)$ & $10(10-20)$ & $20(10-20)$ & $10(0-10)$ \\
\hline
\end{tabular}

${ }^{\star} P<0.05$. Group I = bupivacaine before; Group II = bupivacaine after; Group III = control.

group had a higher average score (corresponding to more severe impairment). The rats that received bupivacaine after induction of the lesion (Group II) had a significantly lower motor functional score until day nine. In terms of stability on the inclined plane, beginning at day three, the animals of the control group always had higher scores, that is to say less neural preservation than the treated rats (Table V).

Sensory test values (thermal stimulus) for the hind paws are shown in Figure 1. There was no significant difference in these values among the three groups at any time.

There was no statistical difference, concerning the occurrence of bladder dysfunction. The percentage of rats that had voiding dysfunction at each evaluation is noted in Figure 2.

At day 18 , in the control group, five of the nine rats $(55 \%)$ had flat SEPs, while none of the animals in Groups I and II had such severe SEP findings. A typical example of SEP from each group is presented in Figure 3. Latencies were longer in the control group than in the treated groups (Table VI). In Group I, this difference in latency reached statistical significance except for Nl $(P=0.06)$. In Group II, only the onset and Pl were significantly shorter than in the control group. SEP amplitudes were significantly higher in Groups I and II than in the control group (Table VII).

The surface area of healthy spinal cord in the centre of the lesion was $2.55 \mathrm{~mm}^{2}\left(1.85\right.$ to $\left.3.3 \mathrm{~mm}^{2}\right)$ in Group I, $2.38 \mathrm{~mm}^{2}$ (1.7 to $2.39 \mathrm{~mm}^{2}$ ) in Group II, and $2.03 \mathrm{~mm}^{2}\left(0.985\right.$ to $\left.2.66 \mathrm{~mm}^{2}\right)$ in the control group $(P>0.05)$. Figure 4 shows spinal-cord sections in a rat from Group I and in a control rat.

\section{Discussion}

Intrathecal bupivacaine administered before or after a spinal cord photochemical lesion in rats improves motor functional scores and SEP findings in the initial post-traumatic period but does not improve the anatomical aspects of the lesion. Thus, intrathecal bupivacaine exhibits functional neuroprotective properties in rats.

The Sprague-Dawley rat model is a well accepted model to study spinal cord neuroprotection. ${ }^{17} \mathrm{~A}$ photochemical lesion at the thoracic spinal level is a recognized model of typical post-traumatic secondary 


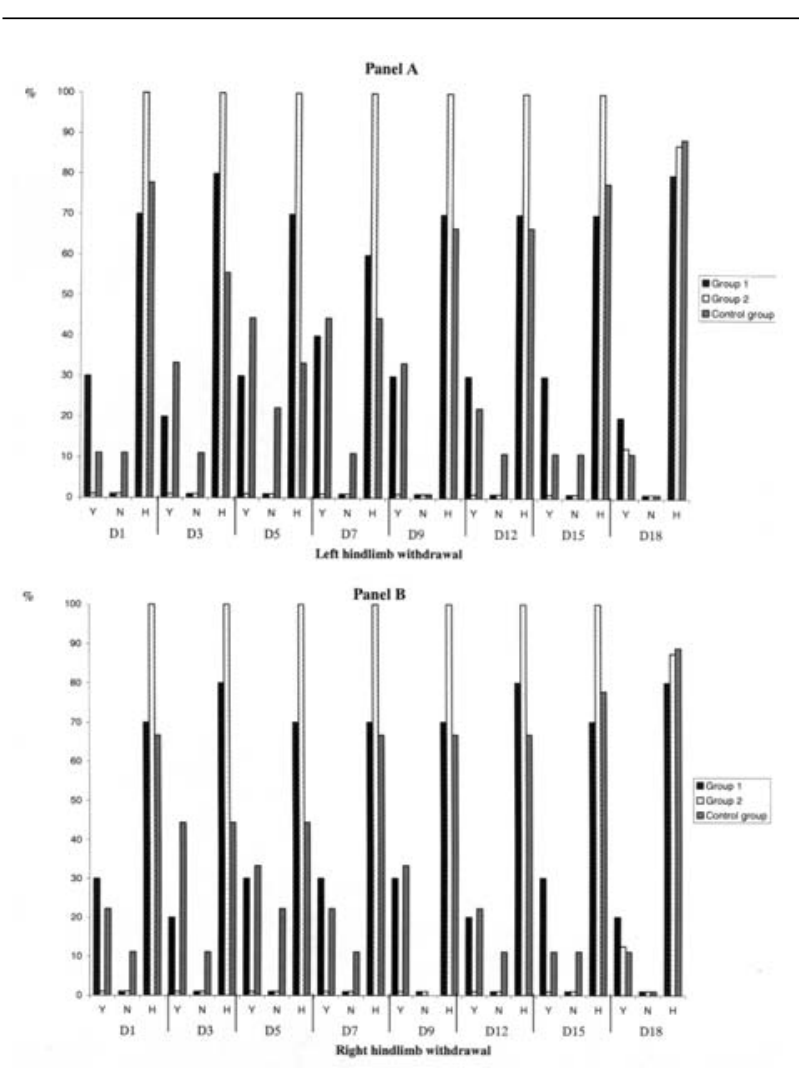

FIGURE 1 Assessment of post-lesional sensitivity using the test of hindlimb withdrawal when touched by a hotplate. Values are expressed as a percentage. $\mathrm{Y}$ (Yes) $=$ hindlimb withdrawal; $\mathrm{N}$ (no) = no hinlimb withdrawal; $\mathrm{H}$ (hyper) = hyperactive flexion (liberated spinal reflex); Panel A: left hindlimb; Panel B: right hindlimb. There was no significant difference among the groups.

lesion. ${ }^{4}$ This model has the advantage of being reproducible and does not require laminectomy in itself.

Several mechanisms may contribute to the neuroprotective action of bupivacaine. In cardiomyocytes, bupivacaine has been shown to block L-type calcium channels and participates in modulation of an as yet unidentified calcium channel. ${ }^{18}$ Few studies on the effect of bupivacaine in neural calcium channels have been reported. In neurons, $\mathrm{N}$-type channels have been found primarily (neuronal type, channels blocked with omega-conotoxin), but also L and T-type channels, which have low thresholds of activation. Tetracaine depresses both high-threshold calcium currents (L and $\mathrm{N}$ types) and low-threshold channels (T-type). Other local anesthetics inhibit high-threshold currents only. Each exerts a different degree of inhibition. ${ }^{19}$ Hirota et al. ${ }^{20}$ clarified the interaction between local

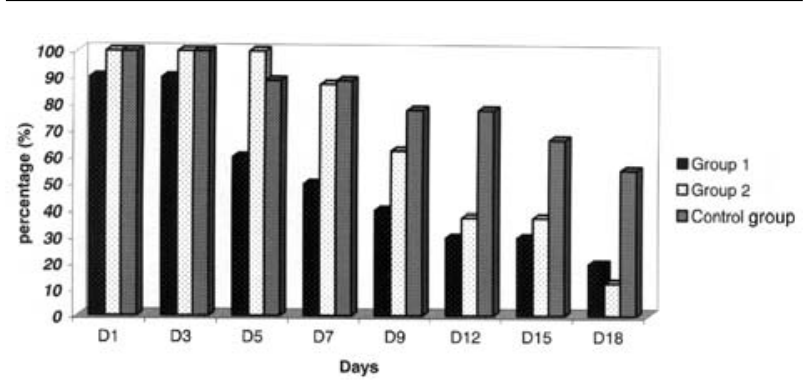

FIGURE 2 Percentage of rats with voiding dysfunction (evaluation of injury to the autonomic nervous system).

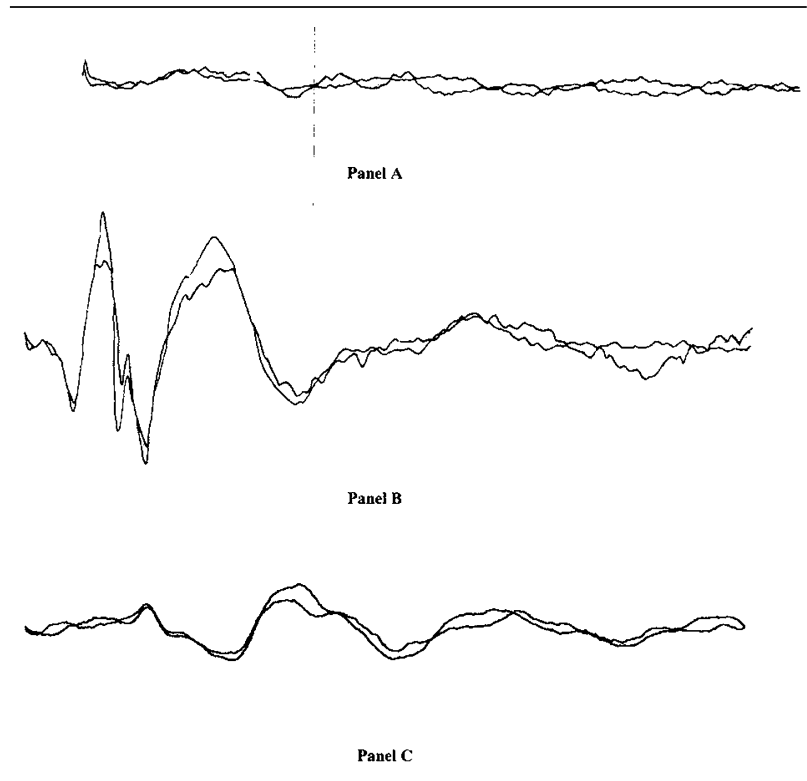

FIGURE 3 Panel A: somatosensory evoked potentials (SEP) recording of a control rat; Panel B: SEP recording of a rat of Group I (bupivacaine before); Panel C: SEP recording of a rat of Group II (bupivacaine after).

anesthetics and L-type channels. Using radiolabelled rat neuron preparations, the latter authors showed that various local anesthetics bind the site of fixation of dihydropyridine in L-type channels. By blocking neuronal calcium channels, bupivacaine prevents the entry of calcium in injured and perilesional cells. In this manner, it reduces the ischemic lesion of the gray matter, the primary element of the secondary lesion. Another important element of the cascade of events leading to cell ischemia is phospholipase activation in 


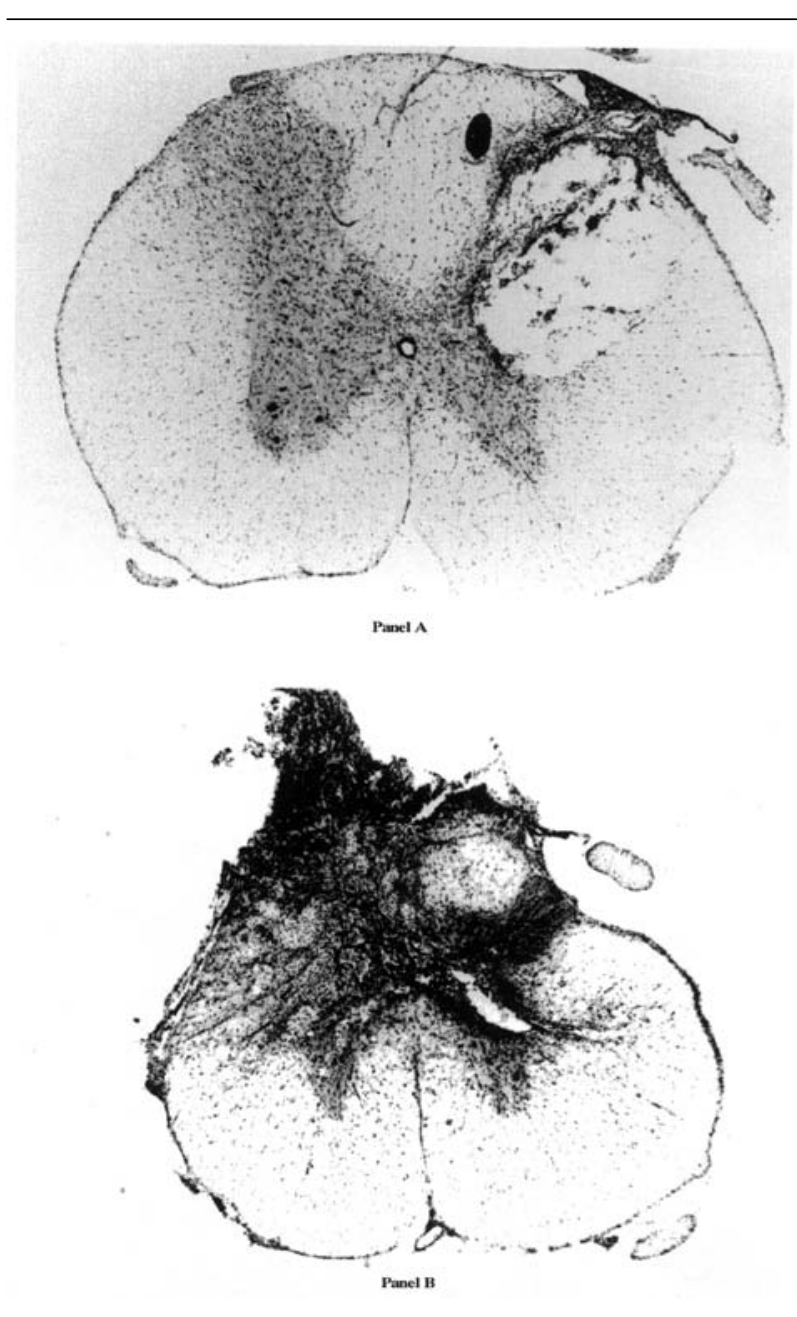

FIGURE 4 Panel A: surface area of an anatomic section of healthy spinal cord at the epicenter of the lesion in a rat of Group I; Panel B: surface area of an anatomic section of healthy spinal cord at the epicenter of the lesion in a control rat. cell membranes. ${ }^{3}$ Bupivacaine is an inhibitor of A2 phospholipase. ${ }^{21}$ However, this inhibition was demonstrated in vitro with high doses of bupivacaine, larger than those used in clinical investigations and reaching cardiotoxic levels. The inhibition of the activity of phospholipase A2 by bupivacaine probably does not explain its neuroprotective effect in vivo. Finally the decrease in cellular glucose consumption observed with intrathecal or epidural bupivacaine ${ }^{22,23}$ might also contribute to its neuroprotective action. Reduced glucose consumption protects against the decrease in glucose stores that develops after spinal-cord injury. This reduces the availability-consumption imbalance.

The mechanism by which the cord lesion was done is different in some aspects from the clinical situation and other animal models where trauma or ischemia produce SCI. It promotes only a local spinal cord ischemia due to vascular stasis. Despite that fact, Breckwoldt et al. ${ }^{5}$ showed a similar effect with intrathecal tetracaine in a model of ischemic SCI by aortic clamping in rabbits. Under general anesthesia, rabbits underwent aortic clamping for 25 or $30 \mathrm{~min}$ after the intrathecal injection of tetracaine or saline. Motor sequelae were less frequent in the treated group than in the controls. This study is consistent with the present findings. Functional motor improvement and protection of the transmission along the sensory tracts demonstrated with SEP are evidence of a neuroprotective effect by bupivacaine against the photochemical model of post-traumatic secondary lesions in rats. In rabbits, Wakamatsu et al. ${ }^{6}$ showed that tetracaine failed to improve neurological and histological outcome after spinal cord ischemia produced by occlusion of the abdominal aorta. However, these authors only analyzed the motor aspect of the lesions (motor scores and histopathological analyses of the ventral horn). In clinical practice, our study primarily suggests that it may be possible to limit the secondary aggravation related to spinal cord trauma. It appears possible, using bupivacaine, to limit the metameric extension of the cord lesion.

TABLE VI Somatosensory evoked potentials (SEP) latencies on day 18 in the three groups; median (25-75th centiles)

\begin{tabular}{lllll}
\hline & Onset & PI & N1 & P2 \\
\hline Group I & $5.44(5.12-6.4)^{*}$ & $10.88(10.56-12.16)^{*}$ & $21.92(20.16-23.68)^{\circ}$ & $32(30.4-35.84)^{*}$ \\
Group II & $5.44(5.44-5.44)^{*}$ & $11.04(10.88-11.2)^{*}$ & $22.88(20.48-24)$ & $36.48(32.48-38.88)$ \\
Group III & $100(6.72-100)$ & $100(11.52-100)$ & $100(22.08-100)$ & $100(37.12-100)$ \\
\hline
\end{tabular}

${ }^{\star} P<0.05 ;{ }^{\circ} \mathrm{P}=0.06$. Group I = bupivacaine before; Group II = bupivacaine after; Group III = Control. All the median latencies were 100 (i.e., conventionally the latency of flat SEP) in the control group. 
TABLE VII Somatosensory evoked potentials (SEP) amplitudes

\begin{tabular}{lll}
\hline & Amplitude $(\mu v)$ & PIN1 NIP2 \\
\hline Group I & $8.72(6.52-10.95)^{*}$ & $9.02(6.34-14.41)^{*}$ \\
Group II & $7.96(6.78-11.7)^{*}$ & $7.77(6.9-10.04)^{*}$ \\
Group III & $0(0-3.24)$ & $0(0-2.76)$ \\
\hline
\end{tabular}

${ }^{*} P<0.05$. Group I = bupivacaine before; Group II $=$ bupivacaine after; Group III = control median amplitudes were zero (value of flat SEP) in the control group.

The SEP objectively evaluates the posterior bundles of the spinal cord. It would have been interesting to perform SEP before creating the lesion as an element of comparison or SEP at day zero immediately after the lesion to document potential changes during recovery over the 18-day period of the experiment. Two recordings were not performed because of the mortality associated with iterative general anesthesia in rats and the morbidity related to repeated dissection of the sciatic nerve and to repeated placement of the epidural electrode. Motor evoked potentials have been used in rats, but were not performed here. This decision was made because of the primarily dorsal topography of the spinal-cord lesion and because motor alterations were assessed by two different functional objective tests.

We used barbiturate anesthesia for this study on SCI. While anesthetic agents are known for their neuroprotective effects, ${ }^{24}$ this property existed for all three groups and was unlikely to influence differences between the groups.

Arterial blood pressure was not measured in these animals. Hemodynamic events after a spinal-cord lesion in rats have been described by Guha et al. ${ }^{25}$ who reported low blood pressures associated with reduced cardiac output and bradycardia. Changes resulting from spinal anesthesia parallel those caused by the lesion. The bupivacaine groups were at risk for shock, ${ }^{26}$ which would have exacerbated spinal-cord lesions. However, Groups I and II exhibited better functional recovery. The effects of potential shock on spinal-cord metabolism were masked by the neuroprotective effect of bupivacaine.

We conclude that functional motor consequences and SEP evidence of damage that develop after a photochemical spinal-cord lesion in rats are reduced by early preventive treatment or post-injury administration of intrathecal bupivacaine. This experimental study found functional, and electrophysiological evidence of the neuroprotective property of bupivacaine injected immediately before or after the creation of a spinal-cord lesion. We speculate that this effect was due to inhibition of calcium entry into neurons by bupivacaine. The present, neuroprotective dose of bupivacaine was that used for anesthetic purposes, but the optimal dose in this indication is not known. In human clinical practice, this study may open perspectives for the medical treatment of post-traumatic secondary lesions.

\section{Acknowledgement}

Henri Haton, for his help.

\section{References}

1 Anonymous. Spinal cord injury: facts and figures at a glance. J Spinal Cord Med 2000; 23: 153-5.

2 Kapadia SE. Ultrastructural alterations in blood vessels of the white matter after experimental spinal cord trauma. J Neurosurg 1984; 61: 539-44.

3 Hall ED, Wolf DL. A pharmacological analysis of the pathophysiological mechanisms of posttraumatic spinal cord ischemia. J Neurosurg 1986; 64: 951-61.

4 Watson BD, Prado R, Dietrich WD, Ginsberg MD, Green $B A$. Photochemically induced spinal cord injury in the rat. Brain Res 1986; 367: 296-300.

5 Breckwoldt WL, Genco CM, Connolly RJ, Cleveland RJ, Diehl JT. Spinal cord protection during aortic occlusion: efficacy of intrathecal tetracaine. Ann Thorac Surg 1991; 51: 959-63.

6 Wakamatsu H, Matsumoto H, Nakakimura K, Sakabe $T$. The effects of moderate hypothermia and intrathecal tetracaine on glutamate concentrations of intrathecal dialysate and neurologic and histopathologic outcome in transient spinal cord ischemia in rabbits. Anesth Analg 1999; 88: 56-62.

7 Bracken MB, Shepard MJ, Collins WF, et al. A randomized, controlled trial of methylprednisolone or naloxone in the treatment of acute spinal-cord injury. Results of the Second National Acute Spinal Cord Injury Study. N Engl J Med 1990; 322: 1405-11.

8 Bracken MB, Shepard MJ, Collins WF Jr, et al. Methylprednisolone or naloxone treatment after acute spinal cord injury: 1-year follow-up data. Results of the second National Acute Spinal Cord Injury Study. J Neurosurg 1992; 76: 23-31.

9 Faden AI. Pharmacotherapy in spinal cord injury: a critical review of recent development. Clin Neuropharmacol 1987; 10: 193-204.

10 Gorio A, Di Guillo AM, Young W. GAl Effects on chemical, traumatic and peripheral nerve induces lesions to the spinal cord. In: Murray M, Goldberger 
ME, Gorio A (Eds). Development and Spasticity of the Mammalian Spinal Cord. NY: Springer Verlag; 1986: 227-42.

11 McIntosh TK, Vink R, Soares H, Hayes R, Simon R. Effect of non competitive blockade of N-methyl-D-aspartate receptors on the neurochemical sequelae of experimental brain injury. J Neurochem 1990; 55: 1170-9.

12 Bracken MB, Shepard MJ, Holford TR, et al. Administration of methylprednisolone for 24 or 48 hours or tirilazad mesylate for 48 hours in the treatment of acute spinal cord injury. Results of the Third National Acute Spinal Cord Injury Randomized Controlled Trial. National Acute Spinal Cord Injury Study. JAMA 1997; 277: 1597-604.

13 Bahar M, Rosen M, Vickers MD. Chronic cannulation of the intradural or extradural space in the rat. $\mathrm{Br} \mathrm{J}$ Anaesth 1984; 56: 405-10.

14 Cameron T, Prado R, Watson BD, Gonzalez-Carvajal $M$, Holets VR. Photochemically induced cystic lesion in the rat spinal cord. I. Behavioral and morphological analysis. Exp Neurol 1990; 109: 214-23.

15 Mimata H, Satoh F, Tanigawa T, Nomura Y, Ogata J. Changes of rat urinary bladder during acute phase of spinal cord injury. Urol Int 1993; 51: 89-93.

16 Baskin DS, Simpson RK Jr. Corticomotor and somatosensory evoked potential evaluation of acute spinal cord injury in the rat. Neurosurgery 1987; 20: 871-7.

17 Pencalet P, Ohanna F, Poulat P, Kamenka JM, Privat $A$. Thienylphencyclidine protection for the spinal cord of adult rats against extension of lesions secondary to a photochemical injury. J Neurosurg 1993; 78: 603-9.

18 Rossner KL, Freese KJ. Bupivacaine inhibition of L-type calcium current in ventricular cardiomyocytes of hamster. Anesthesiology 1997; 87: 926-34.

19 Sugiyama K, Muteki T. Local anesthetics depress the calcium current of rat sensory neurones in culture. Anesthesiology 1994; 80: 1369-78.

20 Hirota K, Browne T, Appadu BL, Lambert DG. Do local anaesthetics interact with dihydropyridine binding sites on neuronal L-type $\mathrm{Ca}^{2+}$ channels? Br J Anaesth 1997; 78: 185-8.

21 Makela A, Kunsi T, Schroder T. Inhibition of serum phospholipase-A2 in acute pancreatitis by pharmacological agents in vitro. Scand J Clin Lab Invest 1997; 57: 401-7.

22 Crosby $G$. Local spinal cord blood flow and glucose utilization during spinal anesthesia with bupivacaine in conscious rats. Anesthesiology 1985; 63: 55-60.

23 Kuroda $\Upsilon$, Sakabe T, Nakakimura K, et al. Epidural bupivacaine suppresses local glucose utilization in the spinal cord and brain of rats. Anesthesiology 1990; 73: 944-50.
24 Patel PM, Drummond JC, Cole DJ, Kelly PJ, Watson M. Isoflurane and pentobarbital reduce the frequency of transient ischemic depolarizations during focal ischemia in rats. Anesth Analg 1998; 86: 773-80.

25 Guba A, Tator CH. Acute cardiovascular effects of experimental spinal cord injury. J Trauma 1988; 28 : 481-90.

26 Van Steenberge A, Joss $S$. Anesthésie péridurale, caudale et rachidienne. In: Flammarion Samii K (Ed.). Anesthésie Réanimation Chirurgicale, 2e ed. Paris; 1995: 528-53. 